\title{
Conditional knockout of N-Myc and STAT interactor disrupts normal mammary development and enhances metastatic ability of mammary tumors
}

\author{
Hawley C. Pruitt ${ }^{1} \cdot$ Brandon J. Metge $^{1} \cdot$ Shannon E. Weeks ${ }^{1} \cdot$ Dongquan Chen $^{2} \cdot$ Shi Wei $^{1} \cdot$ Robert A. Kesterson $^{3} \cdot$ \\ Lalita A. Shevde ${ }^{1,4} \cdot$ Rajeev S. Samant iD $^{1,4}$
}

Received: 26 July 2017 / Revised: 26 September 2017 / Accepted: 23 October 2017 / Published online: 12 January 2018

(c) The Author(s) 2018. This article is published with open access

\begin{abstract}
The process of organ development requires a delicate balance between cellular plasticity and differentiation. This balance is disrupted in cancer initiation and progression. N-Myc and STAT interactor (NMI: human or Nmi: murine) has emerged as a relevant player in the etiology of breast cancer. However, a fundamental understanding of its relevance to normal mammary biology is lacking. To gain insight into its normal function in mammary gland, we generated a mammary-specific Nmi knockout mouse model. We observed that Nmi protein expression is induced in mammary epithelium at the onset of pregnancy, in luminal cells and persists throughout lactation. Nmi knockout results in a precocious alveolar phenotype. These alveoli exhibit an extensive presence of nuclear $\beta$-catenin and enhanced $\mathrm{Wnt} / \beta$-catenin signaling. The Nmi knockout pubertal ductal tree shows enhanced invasion of the mammary fatpad and increased terminal end bud numbers. Tumors from Nmi null mammary epithelium show a significant enrichment of poorly differentiated cells with elevated stem/progenitor markers, active $\mathrm{Wnt} / \beta$-catenin signaling, highly invasive morphology as well as, increased number of distant metastases. Our study demonstrates that $\mathrm{Nmi}$ has a distinct role in the differentiation process of mammary luminal epithelial cell compartment and developmental aberrations resulting from Nmi absence contribute to metastasis and demonstrates that aberration in normal developmental program can lead to metastatic disease, highlighting the contribution and importance of luminal progenitor cells in driving metastatic disease.
\end{abstract}

\section{Introduction}

N-Myc and signal transducer and activator of transcription (STAT) interactor is an evolutionarily conserved, inducible

Electronic supplementary material The online version of this article (https://doi.org/10.1038/s41388-017-0037-7) contains supplementary material, which is available to authorized users.

Rajeev S. Samant

rsamant@uab.edu

1 Department of Pathology, University of Alabama at Birmingham, Birmingham, AL, USA

2 Department of Medicine, University of Alabama at Birmingham, Birmingham, AL, USA

3 Department of Genetics, University of Alabama at Birmingham, Birmingham, AL, USA

4 Comprehensive Cancer Center, University of Alabama at Birmingham, Birmingham, AL, USA cofactor initially identified for its interactions with MYC proteins, as well as STAT transcription factors [1, 2]. Interferon $\gamma$ and $\alpha$, and interleukin- 2 have all been shown to induce N-Myc and STAT Interactor (NMI) expression in a variety of cell types [1]. Moreover, induction of NMI downstream of cytokine stimulation can alter localization and fractionation properties of the NMI protein [2]. Accordingly, it has been proposed that the cellular function of NMI is specific to cell type and potentially even extracellular stimulus [3, 4].

NMI protein expression decreases with progression to later stage disease in breast and gastric carcinoma tissue samples [4, 5]. Strikingly, it is noted that about $70 \%$ of primary breast tumors with evidence of metastatic dissemination show significantly reduced expression of NMI [4]. These reports make understanding its function of high importance, specifically in cancer progression and possibly metastasis. It has been well observed that cancer co-opts developmental processes to aid tumor initiation and progression [6]. However, to date the role of NMI in normal 
developmental processes, as well as tumor initiation and progression in vivo have not been evaluated.

In the current study, we examine the role of Nmi in mammary development, as well as tumor initiation and progression in vivo using a mammary-specific Nmi knockout mouse model. We identify that Nmi loss results in erroneous activation of $\mathrm{Wnt} / \beta$-catenin signaling. This in turn, blocks luminal differentiation and imparts invasive and metastatic characteristics in mammary tumors.

\section{Results}

\section{Nmi expression is upregulated with differentiation of mammary epithelium}

We investigated the expression profile of Nmi protein during different stages of mammary development (Fig. 1a).
Nmi protein expression was detected at the highest levels in mammary epithelial cells during pregnancy and lactation, however; it was also present albeit at low levels during puberty and early involution (Fig. 1b). Immunoscoring revealed a fivefold increase in Nmi expression levels during pregnancy (Fig. 1c). The majority of Nmi staining was observed in the cytoplasm in a speckled, punctate pattern.

Imaging at higher magnification revealed that Nmi protein was clustered at the apical side of the luminal cells within the ducts and alveoli, most concentrated on the side facing the lumen (Fig. 1d). These observations suggested that Nmi protein may have a functional involvement in mammary development.

To investigate the role of Nmi in mammary development, a conditional knockout mouse model specific to the mammary epithelium was generated using a gene targeting approach by inserting loxp sites flanking the eighth and ninth exons of the Nmi gene including the polyadenylation
A

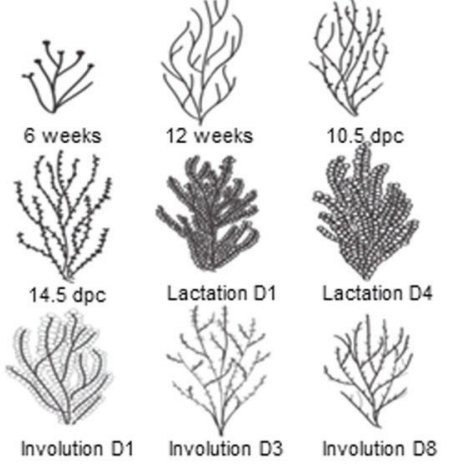

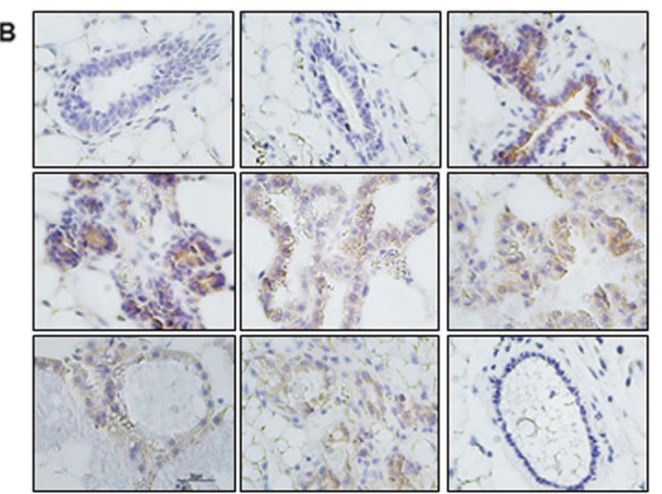

E

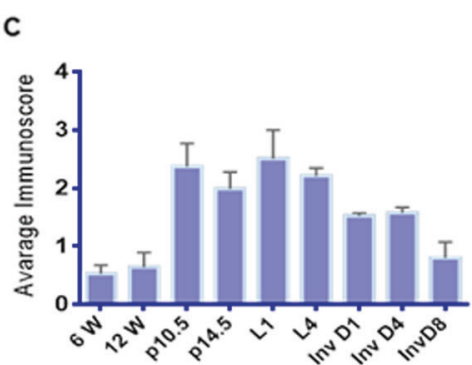

D

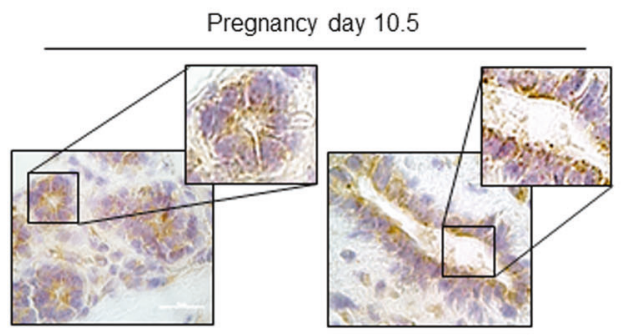

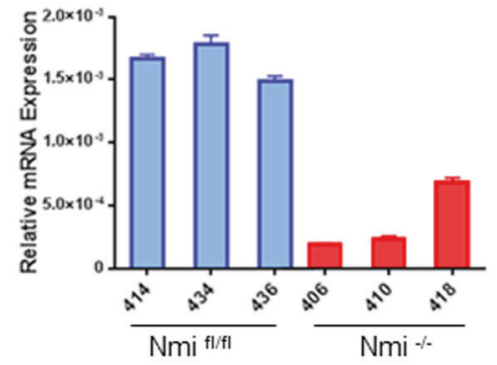

$\mathbf{F}$

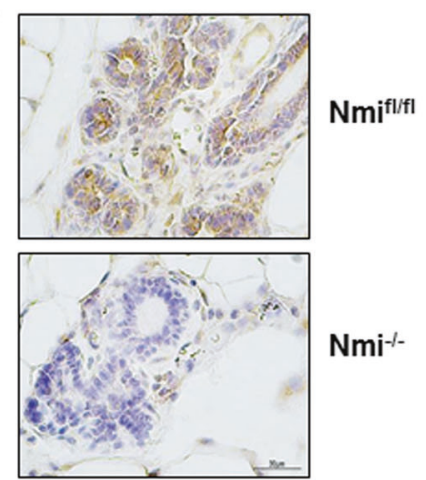

Fig. 1 Nmi expression is upregulated with differentiation of mammary epithelial cells. a Schematic representation of mammary ductal tree at various stages of mammary development (6 weeks, 12 weeks, 10.5 days post conception (dpc), 14.5 days post conception (dpc), lactation day 1 , lactation day 4 , involution day 1 , involution day 3 , and involution day 8 ) were fixed and embedded for immunohistochemical analysis of Nmi expression. b Immunohistochemical analysis of Nmi expression in developing mammary glands. The respective photomicrograph in the $3 \times 3$ array correspond to the stage of development of ductal tree from the $3 \times 3$ array in a. Scale bar $=30 \mu \mathrm{M}$. c Quantitation of Nmi immunostaining. The intensity of staining of cells was assessed as 0 (no staining) to 4 (strongest possible intensity of staining). The immunoscore was derived as the product of the percentage of cells at each intensity and the corresponding intensity. The products were added to get an immunoscore for the section. d In all, $100 \times$ photomicrographs of Nmi staining in ductal and alveolar cells of the mammary epithelium 10.5 days post conception. e Level of Nmi mRNA transcript in control $\left(\mathrm{Nmi}^{\mathrm{f} / \mathrm{fl}}\right)$ mice compared with knockout $\left(\mathrm{Nmi}^{-1-}\right)$. Nmi mRNA is reduced 10fold in the in $\mathrm{Nmi}^{-1-}$ mice. The numbers are mouse identifiers. $\mathbf{f}$ Immunohistochemical analysis of Nmi protein in mammary epithelial cells. Top and bottom images correspond to mice lacking and expressing K-14 Cre, respectively. Scale $\mathrm{bar}=30 \mu \mathrm{M}$ 
sequence (Supplementary Fig. 1A). Cre-mediated excision of the loxp- flanked region in keratin 14-expressing cells destabilized the mRNA transcript thereby targeting it for nonsense-mediated decay. Total RNA from isolated mammary epithelial cells shows a 10-fold decrease in Nmi mRNA transcript levels (Fig. 1e). Moreover, immunohistochemical staining shows a total loss of Nmi protein expression specifically in the mammary epithelium of Crepositive mice (Fig. 1f). Western blot analysis of isolated mammary epithelial cells at multiple stages of mammary development confirmed that Nmi protein is notably absent thought mammary development (Supplementary Fig. 1B).

\section{Conditional knockout of $\mathrm{Nmi}$ in the mammary epithelium alters mammary development}

Phenotypic characterization of the Nmi knockout mice revealed significantly enhanced ductal extension during pubertal mammary development, as well as increased terminal end bud number (Fig. 2a). Furthermore, knockout mice exhibited prolific alveologenesis during mid pregnancy at day 14.5 post conception (Supplementary Fig. 2A), an observation that was quantified in hematoxylin and eosin (H\&E) sections (Supplementary Fig. 2B). Consequently, they also exhibited a vividly augmented alveologenesis
A

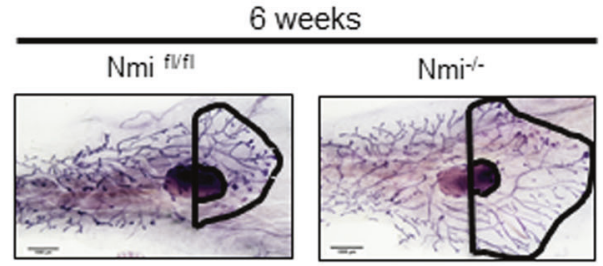

Ductal Extension

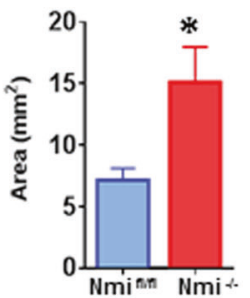

Terminal End Buds

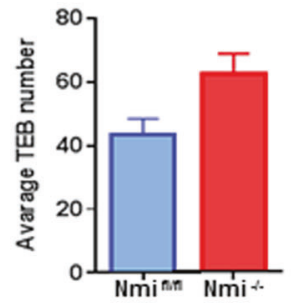

B

Lactation Day 1
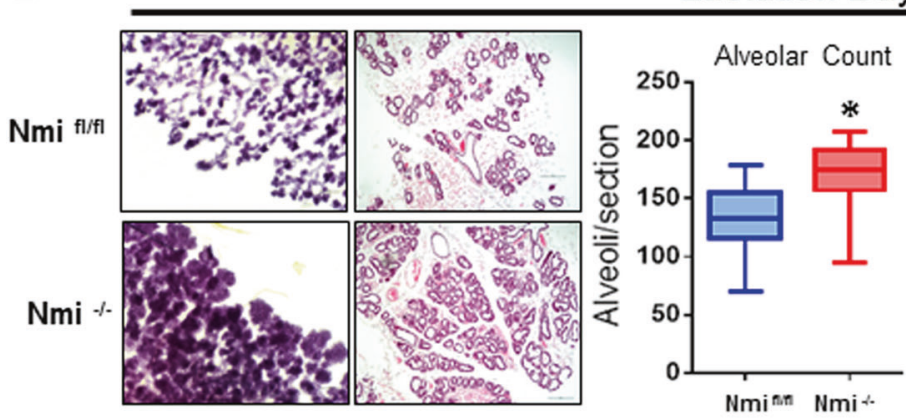

D
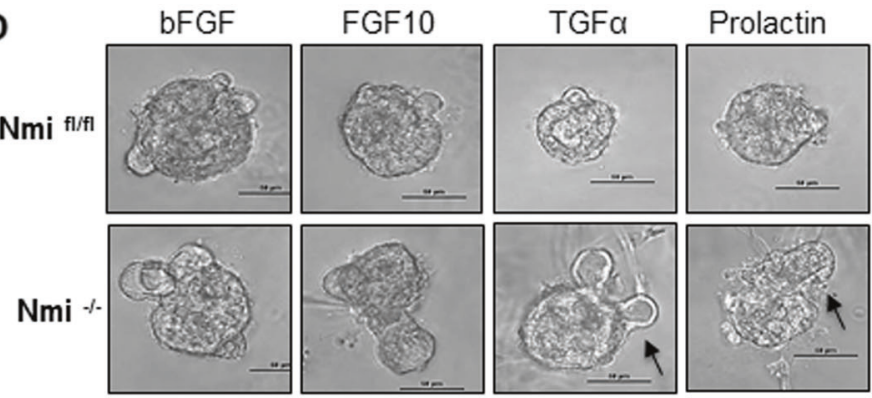

C
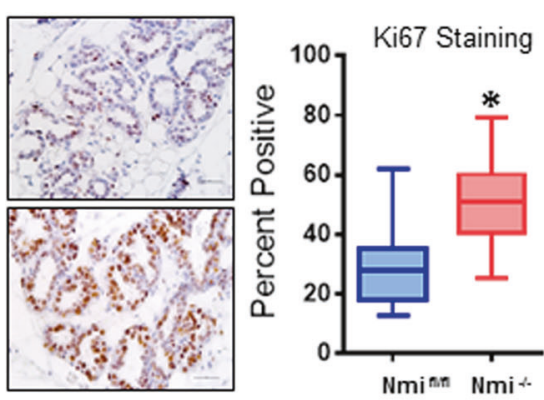

E

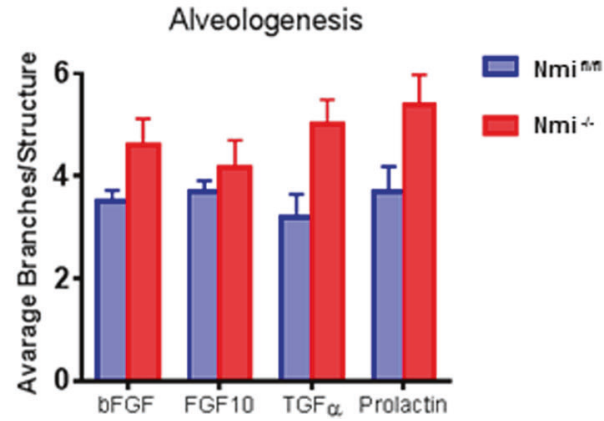

Fig. 2 Knockout of Nmi in the mammary epithelium alters mammary development. a Whole-mounted mammary glands from Nmi knockout mice and littermate controls. Ductal area in $\mathrm{mm}^{2}$ was measured by drawing a perpendicular line through the lymph node while excluding the area of the lymph node. Scale bar $=1000 \mu \mathrm{M} ; N=5$ control mice $\left(\mathrm{Nmi}^{\mathrm{f} / / \mathrm{fl}}\right)$ and $4 \mathrm{KO}$ mice $\left(\mathrm{Nmi}^{--}\right), * p<0.05$. b Mammary glands at lactation day 1 from Nmi KO and age matched control mice. Wholemounted mammary glands and histological photomicrographs depict alveolar structures. Alveoli were quantified in H\&E-stained sections and plotted as number of alveoli per section of mammary gland; Scale bar $=50 \mu \mathrm{M} ; N=5$ control mice $\left(\mathrm{Nmi}^{\mathrm{fl} / \mathrm{fl}}\right)$ and $4 \mathrm{KO}$ mice $\left(\mathrm{Nmi}^{-/-}\right)$, $* p=0.001$. $\mathrm{c}$ Ki67 was used to quantify proliferating cells in alveoli. The percent of Ki67-positive cells per field of view is plotted; Scale bar $=5 \mu \mathrm{M} ; N=5$ control mice $\left(\mathrm{Nmi}^{\mathrm{f} / \mathrm{fl}}\right)$ and $4 \mathrm{KO}$ mice $\left(\mathrm{Nmi}^{-l-}\right),{ }^{*} p$ $=0.0001$. $\mathrm{d}$ Isolated mammary epithelial cells from mature nonparous mice were embedded in matrigel and stimulated with growth factors known to promote alveologenesis. Arrows indicate structures counted as individual branches on organoids. e Alveologenesis is plotted as average number of branches/structure. This experiment was repeated three times. $* p<0.05$ 
during lactation day 1 (L1) as demonstrated by wholemount and H\&E staining (Fig. 2b), although Nmi knockout mice did not display any noticeable deficiency in lactation. Mammary epithelial cells in Nmi knockout mice were more starkly proliferative at $\mathrm{L} 1$ as demonstrated by the increased percentage of Ki67-positive cells (Fig. 2c).

To determine whether this effect was due to stromal crosstalk or intrinsic characteristics of the cells, mammary epithelial cells from Nmi knockout and littermate controls were isolated, enriched, and placed into three-dimensional (3D) culture. Organoids were exposed to proliferative stimuli present during various stages of mammary development in mice predominantly during ductal branching and lactation (Fig. 2d). Organoids from Nmi knockout mice exhibited a trend toward enhanced alveologenesis (measured by the number of branches per organoid) when exposed to members of the fibroblast growth factor (FGF) family. Notably, significant differences were observed after treatment with transforming growth factor $\alpha(\mathrm{TGF} \alpha)$ and prolactin, factors present during pregnancy and lactation (Fig. 2e).

\section{Nmi loss promotes Wnt/ $\beta$-catenin signaling during normal mammary development}

To determine how the loss of Nmi contributed to a hyperproliferative phenotype during puberty and lactation, we performed global RNAseq analysis from enriched mammary epithelial organoids from L1, the time point when Nmi protein expression in normal mammary epithelium is at its highest level. Ingenuity pathway analysis revealed that molecular events that pertain to cellular development,

\section{A}

\section{Cellular and Molecular Functions}

\begin{tabular}{lcc} 
Name & p-value & \#Molecules \\
\hline Cell-To-Cell Signaling and Interaction & $2.55 \mathrm{E}-02-3.02 \mathrm{E}-05$ & 33 \\
Cellular Movement & $2.63 \mathrm{E}-02-9.45 \mathrm{E}-05$ & 18 \\
Cellular Function and Maintenance & $2.26 \mathrm{E}-02-1.78 \mathrm{E}-04$ & 26 \\
Cellular Development & $2.56 \mathrm{E}-02 \cdot 2.82 \mathrm{E}-04$ & 30 \\
Cellular Growth and Proliferation & $2.57 \mathrm{E}-02-2.82 \mathrm{E}-04$ & 35
\end{tabular}

Lactation Day 1

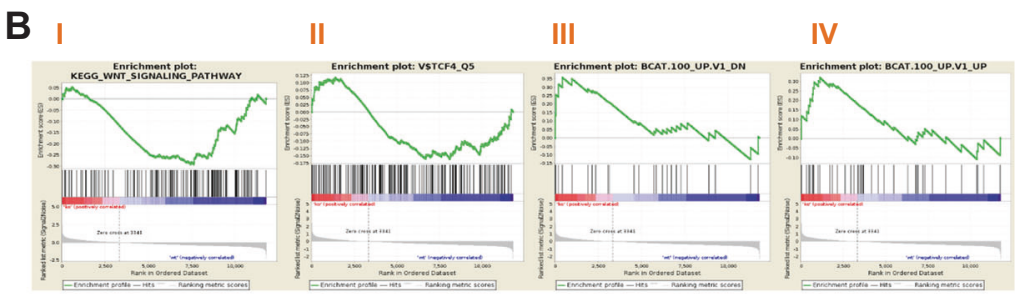

C

-catenin
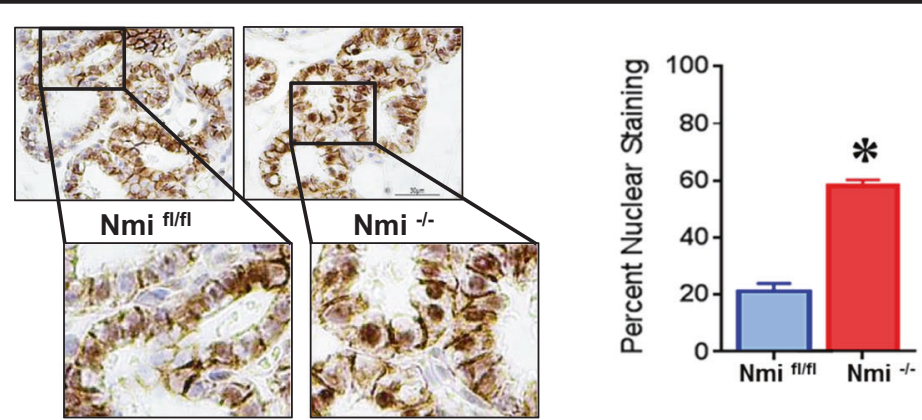

D
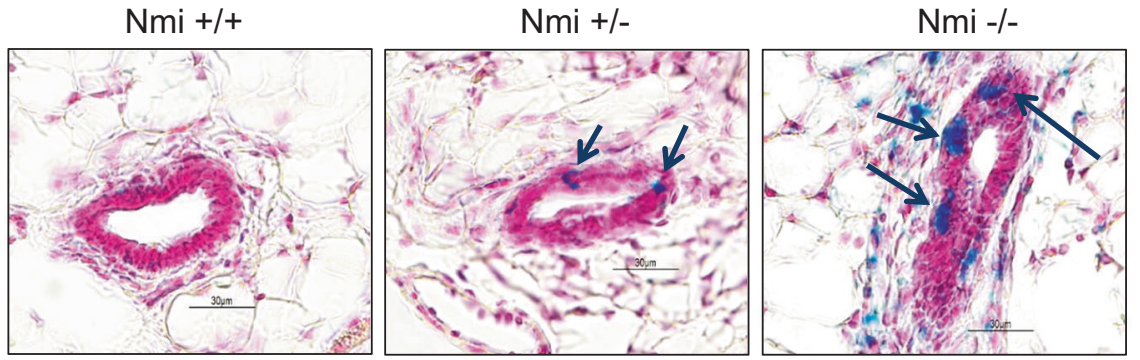

Fig. $3 \mathrm{Nmi}$ loss promotes $\mathrm{Wnt} / \beta$-catenin signaling during normal mammary development. a Ingenuity pathway analysis of differentially expressed messages from RNAseq analysis of mammary epithelium from lactating glands from knockout mice. b Gene set enrichment analysis of total RNA from lactating mammary glands of three control and three knockout mouse shows overlap with the I. Wnt signaling KEGG pathway, II. TCF4 target genes, and III, IV transcriptomes of cells with constitutively active $\beta$-catenin. $\mathbf{c}$ Lactating mammary glands
$\mathrm{Nmi}^{\mathrm{f} / \mathrm{fl}}$ and $\mathrm{Nmi}^{-/-}$mice were stained for total $\beta$-catenin. Quantification of staining shows an increased percentage of nuclear $\beta$-catenin in $\mathrm{Nmi}^{-1-}$ mammary epithelium $(p<0.05 n=3$ control and 4 knockout mice). d Mammary glands from 6-week-old bat-gal mice with $\mathrm{Nmi}^{\mathrm{f} / \mathrm{fl}}$, $\mathrm{Nmi}^{+/-}$and $\mathrm{Nmi}^{-/-}$genetic background were evaluated $\beta$-galactosidase activity using X-gal as substrate. Blue color is indicative of active $\beta$-galactosidase. Sections were counterstained with nuclear fast red. Arrows indicate regions of active $\beta$-galactosidase. * indicates $P<0.05$ 
growth, and proliferation were significantly enriched with Nmi loss (Fig. 3a). Gene set enrichment analysis identified the Wnt/ $\beta$-catenin signaling pathway as having significant enrichment. Curated data sets from the Kegg database (Fig. 3b I), as well as TCF4 target genes curated by the Broad Institute (Fig. 3b II) were identified from GSEA. Additionally, two data sets from cells expressing constituitively active $\beta$-catenin were also revealed (Fig. 3b III, IV) [7].

Wnt signaling is an active part of mammary gland development and uncontrolled activation of this pathway causes abnormal ductal extension and precocious alveolar development [8]. To confirm the presence of activated Wnt signaling during lactation in vivo, mammary glands were stained for $\beta$-catenin and localization was scored in control and knockout glands. Nmi knockout glands exhibited a significantly higher percentage of cells with nuclear $\beta$ catenin. This staining is indicative of elevated presence of transcriptionally active $\beta$-catenin in the mammary epithelium of Nmi knockout mouse (Fig. 3c).

To confirm the effect on the transcriptional readout of Wnt signaling in vivo, we crossed mammary-specific Nmi knockout mice to the Wnt reporter BAT-gal strain. At 6 weeks of age, mammary glands were analyzed from control and knockout mice for $\beta$-galactosidase activity; indicative of active $\mathrm{Wnt} / \beta$-catenin signaling. Glands from homozygous knockout mice exhibited a stark increase in the number of blue-stained cells within the ducts of the mammary gland compared with controls, which had very few blue epithelial cells.

Interestingly, glands from heterozygous mice also showed noticeable positive staining (Fig. 3d). These observations clearly confirmed that lack of Nmi expression in vivo is activating $\mathrm{Wnt} / \beta$-catenin signaling.

\section{Nmi loss in MMTV-Neu mammary glands drives accumulation of luminal progenitors by blocking differentiation and activating $\beta$-catenin}

We hypothesized that Nmi loss could impact the differentiation of luminal cells by activating Wnt signaling. To first query this in vitro, we utilized HC11, a murine mammary epithelial cell line that allows for modeling mammary epithelial differentiation in response to a prolactin stimulus. These cells were isolated from a mid-pregnant mouse and have been shown to represent the alveolar branch of the luminal lineage [9-11]. Nmi protein expression increased in a time-dependent manner with exposure of HC11 cells to differentiation media containing prolactin, insulin, and dexamethasone. These observations corroborated our in vivo finding. Upregulation of Nmi was concomitant with an increase in $\beta$-casein levels, a bona fide marker of differentiation of the $\mathrm{HC} 11$ cell line, suggesting that Nmi may play a functional role in this differentiation process
(Fig. 4a). To determine the effect of Nmi loss, we stably knocked down Nmi expression using two independent short hairpin RNA constructs. Nmi knockdown cells produced significantly less $\beta$-casein mRNA and protein when stimulated with differentiation media compared with the nontargeting control cells. In addition, levels of phosphorylated $\beta$-catenin at residue ser552 (indicative of nuclear and transcriptionally active $\beta$-catenin) in Nmi knockdown cells were concomitantly increased. This indicated that these cells are deficient in undergoing differentiation (Fig. 4b).

To understand whether this lack of differentiation could influence the progression of mammary tumors in vivo, we crossed the mammary-specific Nmi knockout mouse with the MMTV-Neu transgenic tumor model. The preneoplastic mammary glands of the MMTV-Neu $\mathrm{Nmi}^{-/-}$ mice retained the proliferative alveolar phenotype (Fig. 4c). The mammary glands exhibited significantly more nuclear $\beta$-catenin, a possible mechanism for the alveolar hyperplasia (Fig. 4d). Flow cytometry analysis of these glands revealed an expansion of CD49f CD61 double-positive cells in Nmi null mammary epithelium, a population identified to be luminal progenitors and potentially, the cells that originate MMTV-neu tumors [12] (Fig. 4e).

\section{Nmi loss changes tumor characteristics and enhances metastasis in two models of spontaneous mammary carcinoma}

Tumors derived from conditional Nmi knockout mice on the MMTV-Neu background exhibited significantly shorter latency (Fig. 5a) and overall tumor growth was accelerated significantly although modestly (Fig. $5 b$ ). To examine the role of Nmi loss on metastasis in vivo, Nmi knockout MMTV-Neu mice were examined for the presence of metastatic lesions. Lesions observed by $\mathrm{H} \& \mathrm{E}$ were confirmed through Her2-positive immunostaining (Fig. 5c). Nmi knockout mice overall had a significantly higher incidence of metastasis while also harboring tumors that formed more pulmonary metastases (Fig. 5d top, bottom). To evaluate the effect of Nmi loss independent of the Neu oncogene background, we investigated the impact of a carcinogen on the Nmi knockout mice. The conditional Nmi knockout mice and littermate controls were implanted with a $50 \mathrm{mg}$ slow release medroxyprogesterone acetate pellet subcutaneously at 6 weeks of age. Mice were then orally administered with $1 \mathrm{mg}$ 7,12-dimethylbenz[a]anthracene (DMBA) carcinogen, dissolved in sesame oil at 9, 10, 12, and 13 weeks of age (Fig. 5e). The median tumor onset in both groups occurred at about 50 days post final DMBA treatment dose, there was no significant difference in control and Nmi knockout groups (Fig. 5f). Additionally, tumor growth rate did not change significantly between groups (Fig. 5g). When the mean tumor diameter reached 
A

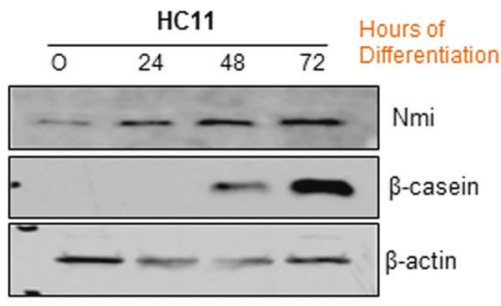

B

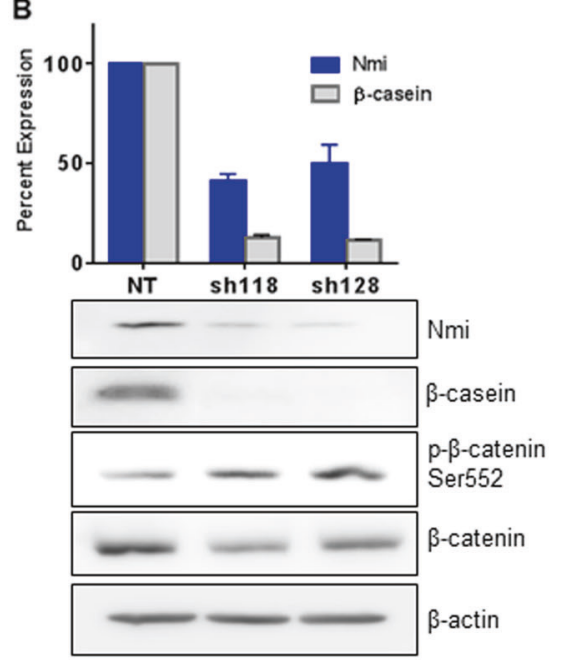

C

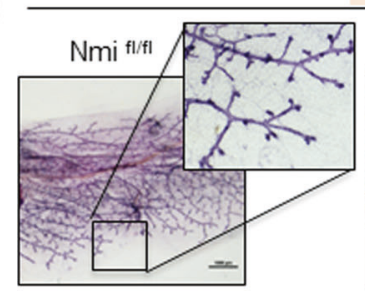

MMTV-Neu

D
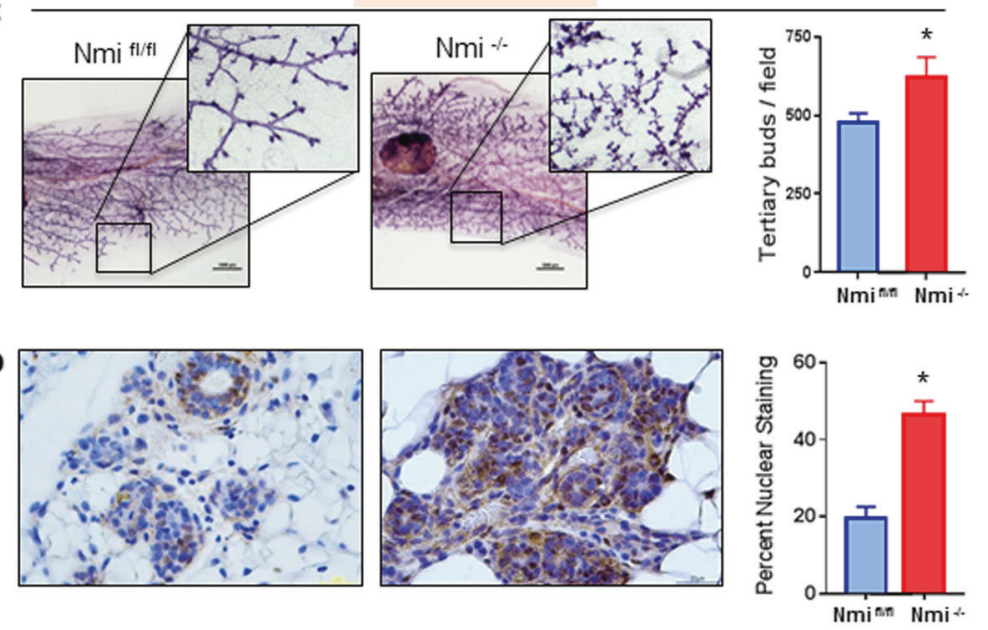

$\mathbf{E}$
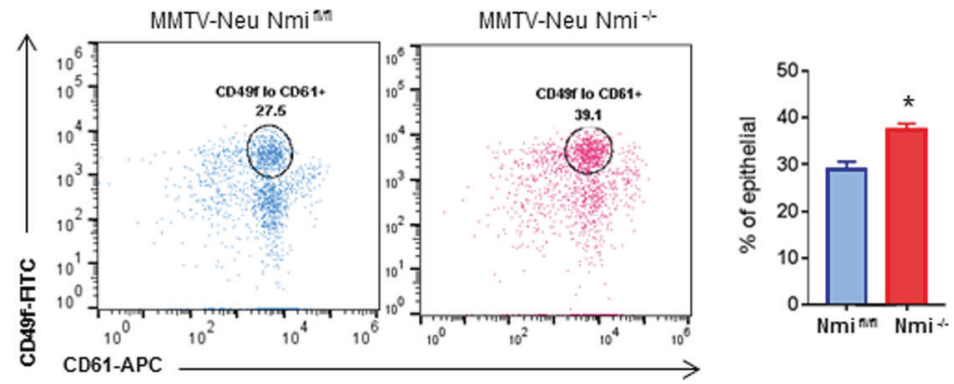

Fig. 4 Nmi loss in MMTV-Neu mammary glands increases population of luminal progenitor cells by blocking differentiation and activating $\beta$ catenin. a HC11 cells were induced to differentiate over a course of 72 $\mathrm{h}$ with media replenishment every $24 \mathrm{~h}$. Western blot analysis shows that $\mathrm{Nmi}$ as well as $\beta$-casein expression increases progressively with exposure to differentiation medium. b $\mathrm{HC} 11$ cells were differentiated with prolactin, dexamethasone, and insulin for $72 \mathrm{~h}$. Knockdown of $\mathrm{Nmi}$ in two independent clones (sh118 and sh128) decreases transcript and protein levels of $\beta$-casein, a marker of alveolar differentiation. Both Nmi knockdown clones show increased phosphorylation of $\beta$ catenin at residue 552. c Evaluation of tertiary budding from whole mounts from control $\left(\mathrm{Nmi}^{\mathrm{f} / \mathrm{fl}}\right)$ and $\mathrm{Nmi}$ knockout $\left(\mathrm{Nmi}^{-/-}\right)$MMTVneu nonparous mice. Glands from $\mathrm{Nmi}^{-1-}$ mice display on average 150 more tertiary buds/field than control MMTV-neu mice $(n=7$ mice per group) Scale bar $=1000 \mu \mathrm{M}, * p=0.01$. d Mammary glands from nulliparous $\mathrm{Nmi}^{\mathrm{f} / \mathrm{fl}}$ MMTV-neu and $\mathrm{Nmi}^{-1-}$ MMTV-neu mice were stained for $\beta$-catenin. $\mathrm{Nmi}^{-1-}$ MMTV-neu exhibit $25 \%$ more nuclear $\beta$ catenin staining compared with controls, $n=4$ MMTV-Neu Nmi ${ }^{\mathrm{f} / \mathrm{fl}}$ and 6 MMTV-Neu Nmi ${ }^{-1-}, * p=0.0001$. e Mammary epithelial cells from $\mathrm{Nmi}^{\mathrm{fl} / \mathrm{fl}}$ MMTV-neu and $\mathrm{Nmi}^{-/-}$MMTV-neu mice were analyzed by flow cytometric analysis for the presence of the progenitor population. After the exclusion of lineage, positive cells (CD45, CD31, and Ter119) were sorted for expression levels of CD49f and CD61. Gates were established according to the fluorescence minus one controls. Double-positive cells were quantified and plotted as the percentage of epithelial cells ( $n=4$ controls and 6 knockouts) $* p=0.03$ approximately $10-12 \mathrm{~mm}^{2}$ mice were necropsied, lungs fixed in Bouins solution, and examined for external metastatic nodules (Fig. 5h). The number of metastatic nodules on lungs of tumor-bearing Nmi knockout mice was roughly double the number of nodules found on lungs of control mice, confirming a distinct role for Nmi in metastatic dissemination of tumor cells (Fig. 5h).

\section{Carcinogen and MMTV-Neu induced Nmi null tumors exhibit invasive morphological features}

To thoroughly assess the growth characteristics of Nmi knockout tumor cells from MMTV-Neu and carcinogeninduced tumors, cells were dissociated from the extracellular matrix. Tumor cell clusters where allowed to adhere in two-dimensional culture or overlaid onto a solid layer of 3D matrix surrounded by media containing $2 \%$ matrix (Fig. 6a).

Following attachment to culture plates, carcinogeninduced and MMTV-neu tumor cells with and without Nmi were visualized using phase contrast microscopy. The most striking difference between tumor cells of different genotypes from both models was the presence of cells with numerous invasive projections at the leading edge of the colonies (foci)s from Nmi knockout animals. Cells at the leading edge from control mice exhibited far fewer protrusions ( $n=4$ controls and 6 knockout tumors). Interestingly, this phenomenon was recapitulated in vivo in uninvolved 


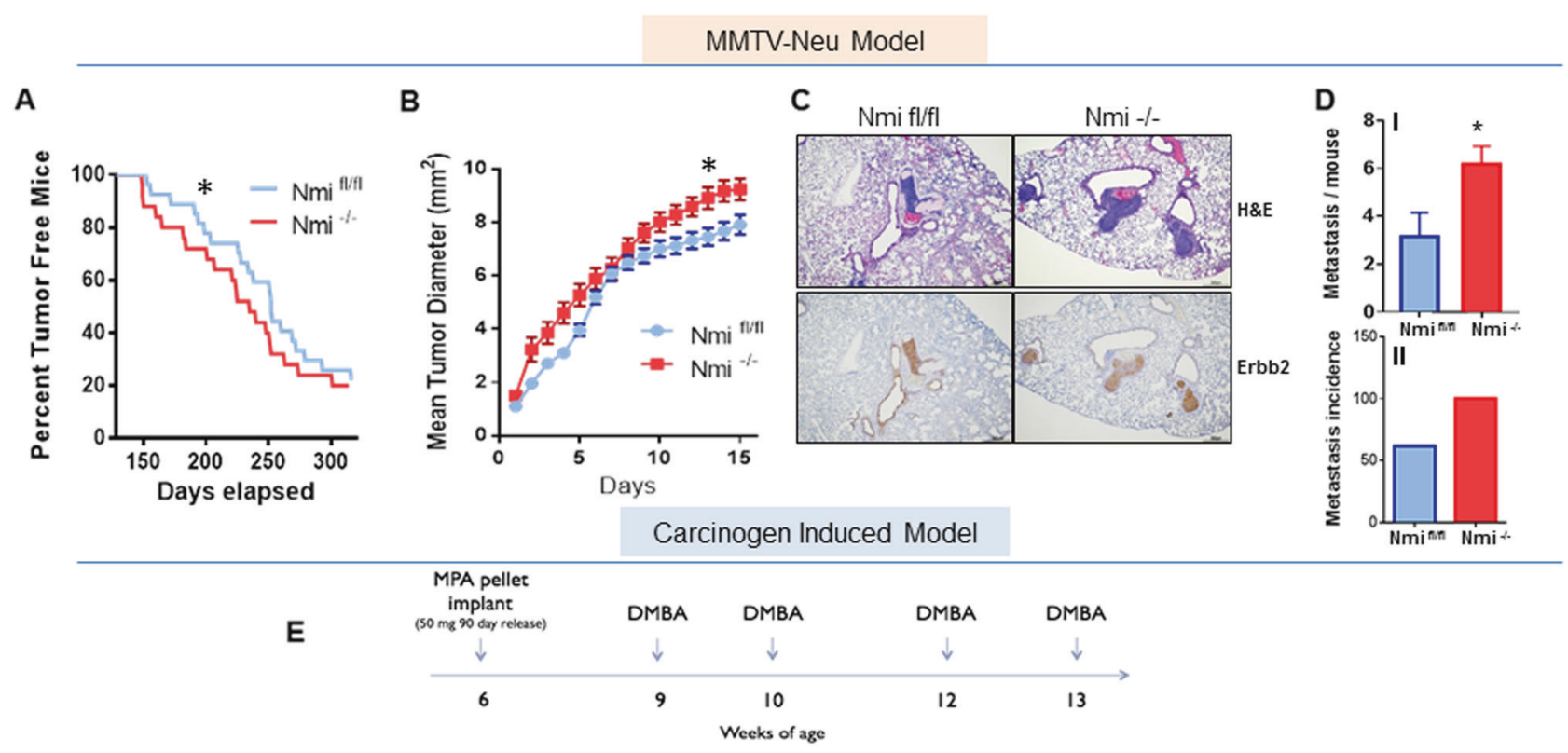

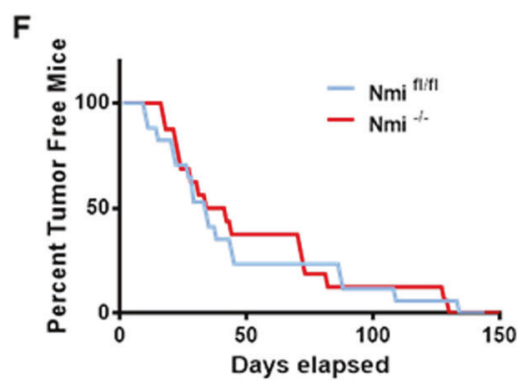

Fig. $5 \mathrm{Nmi}$ loss enhances spontaneous metastasis of mammary cancer. a MMTV-Neu $\mathrm{Nmi}^{-/-}$mice displayed early tumor incidence compared with their littermate controls $(n=26$ controls and 25 knockout) $* p=$ 0.00196 by log-rank test. b The growth rate of tumors depicted as mean tumor diameter was also enhanced in MMTV-Neu Nmi ${ }^{-l-}$ mice ( $n=25$ control and 25 knockout). $* p<0.0001$ by linear regression test. c Lung sections from MMTV-Neu Nmi ${ }^{\mathrm{f} / \mathrm{fl}}$ and MMTV-Neu Nmi ${ }^{-I-}$ were stained with hematoxylin and eosin. Metastatic dissemination of the Erbb2 mammary epithelial cells was confirmed using immunohistochemical analysis of serial sections. $\mathbf{d}$ Incidence and number of metastasis in Nmi knockout mice was increased $\left(n=12 \mathrm{Nmi}^{\mathrm{f} / / \mathrm{l}}, 17\right.$

mammary glands of carcinogen-treated mice. Glands were dissected from and whole mounts were performed to visualize cellularly dense areas. Control mice formed small lesions with very stark borders that seemed to be confined and less invasive. In contrast, invasive fronts of preneoplastic lesions in Nmi knockout mice were much more difficult to visualize because of microscopic projections of epithelial cells into the surrounding stroma (Supplementary Fig. 3A). Upon histological examination, dense cell clusters in knockout mice visually invaded into the surrounding stroma (Supplementary Fig. 3B). This morphological phenotype was also observed in $3 \mathrm{D}$ culture where $\mathrm{Nmi}$
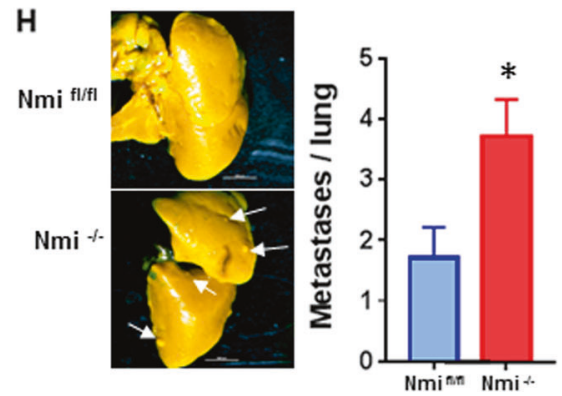

$\left.\mathrm{Nmi}^{-1-}\right) * p=0.02$. e Schematic of strategy for generating DMBA/ medroxyprogesterone acetate (MPA)-induced mammary tumors. Nmi knockout mice were implanted with a $50 \mathrm{mg} / 90$-day release MPA pellet subcutaneously as 6 weeks of age. At $9,10,12$, and 13 weeks of age, $1 \mathrm{mg}$ DMBA was administered orally to induce carcinogenesis. $\mathbf{f}$ DMBA/MPA induced mammary tumors in $\mathrm{Nmi}^{-1-}$ mice displayed no significant difference in tumor incidence compared with their littermate controls $\left(n=17 \mathrm{Nmi}^{\mathrm{fl} / \mathrm{fl}}\right.$ and $\left.16 \mathrm{Nmi}^{-/-}\right)$. g Tumor growth rate did not differ between control and knockout mice $\left(n=15 \mathrm{Nmi}^{\mathrm{f} / \mathrm{fl}}\right.$ and $14 \mathrm{Nmi}$ ${ }^{-/}$). h Nmi knockout mice showed increased lung metastasis/mouse compared with controls $(n=14$ control, $12 \mathrm{KO}) * p=0.02$. The photomicrographs show representative lungs

knockout organoids form numerous buds extending out into the surrounding matrix (Fig. 6b).

Projections from individual organoids were visualized more specifically through phalloidin staining of fibrillar actin. Overlays show tumor cells at the leading edge of Nmi knockout organoids extending projections containing fibrillar actin into the surrounding area (Fig. 6c). The invasive ability of MMTV-Neu control and knockout cells was quantified using a Boyden chamber invasion assay. Single tumor cells from Nmi knockout mice invaded through Matrigel coated Boyden chambers more effectively than control counterparts (Fig. 6d). 


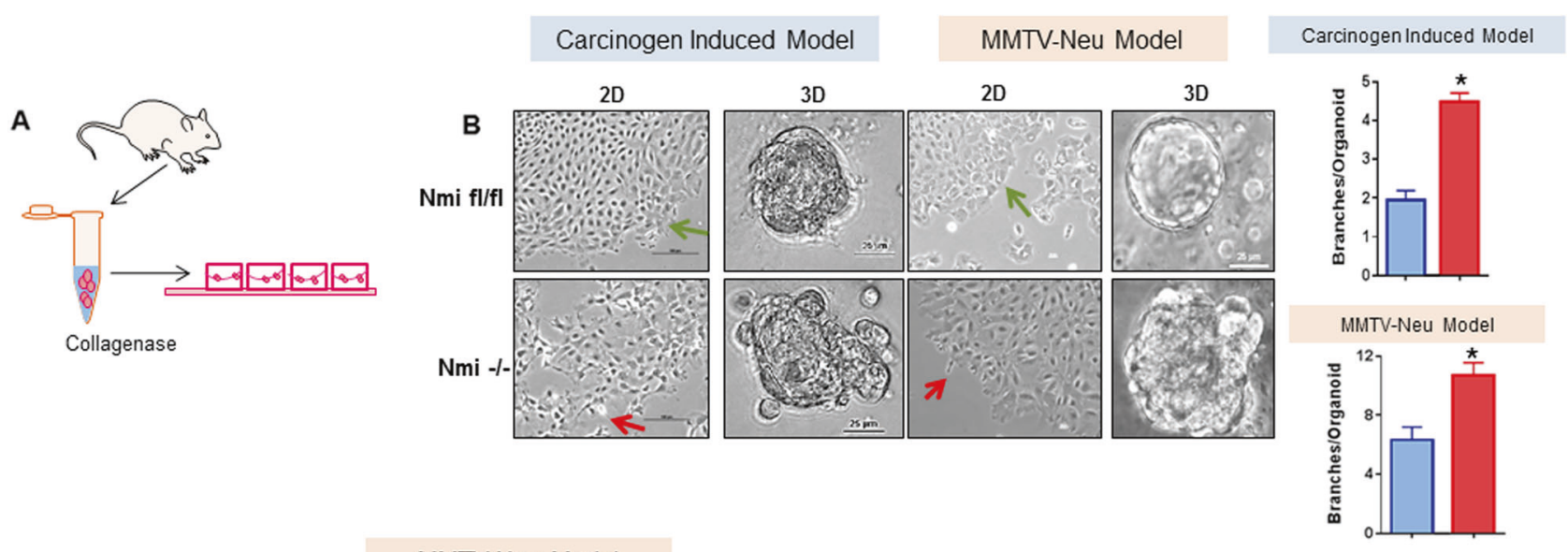

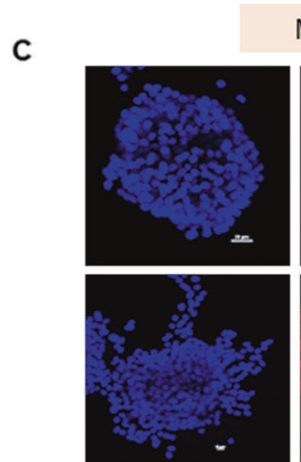

DAPI
MMTV-Neu Model

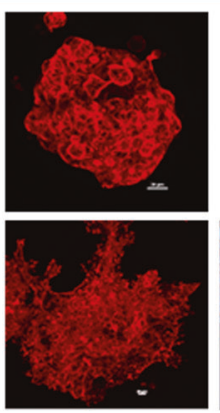

Phalloidin

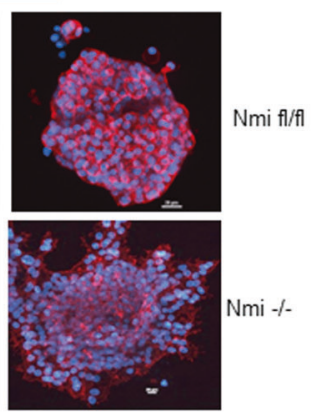

Overlay

D

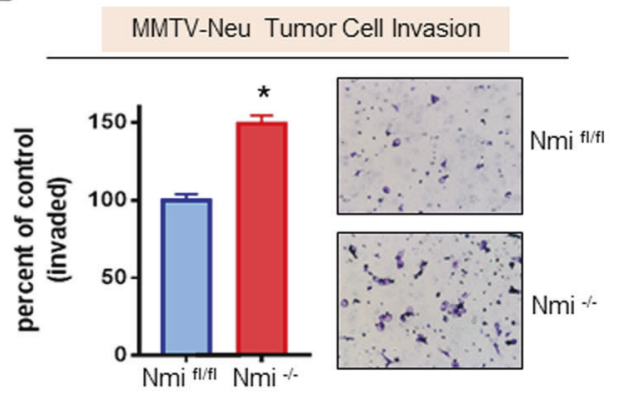

Fig. 6 Carcinogen and MMTV-Neu induced Nmi null tumors exhibit invasive morphological features. a Schematic for establishing 3D organoid cultures: tumors from control and knockout models were excised and digested using collagenase $(10 \mathrm{mg} / \mathrm{mL})$ and pronase $(0.1$ $\mathrm{mg} / \mathrm{mL}$ ) at $37^{\circ} \mathrm{C}$ to separate tumor cells from the extracellular matrix. Organoids from tumors were overlaid onto 3D matrix (cultrex) in chamber slides (Millipore). b Morphologic behavior of control and Nmi knockout tumor cells was studied in 2 or 3-dimensional growth conditions. For 2D growth, tumor cells were allowed to attach to culture dishes and imaged prior to passaging. The 3D organoid cultures were established as described in the schematic a. Photomicrographs show phase contrast images of 2D and 3D cultures. The 3D culture images were captured after 14 days of culture to examine invasive processes. Scale bar $=100 \mu \mathrm{M}$ for $2 \mathrm{D}$ cultures and $25 \mu \mathrm{M}$ for $3 \mathrm{D}$ cultures. Green arrows in 2D images indicate smooth/cohesive edges of

\section{Carcinogen and MMTV-Neu induced Nmi null tumors contain fewer differentiated cell populations and activated $W n t / \beta$-catenin signaling}

The carcinogen-induced model produces heterogeneous tumors that can be separated into distinct luminal and basal populations (Supplementary Fig. 4A). Phenotypic characterization of these tumors revealed that the likely tumorinitiating cell is derived from the basal compartment of the mammary gland; however, this clone differentiates into luminal cells, including cells, which express hormone receptors [13]. Carcinogen-induced tumors from conditional Nmi knockout mice have an expansion of the basal colonies whereas red arrows indicate non cohesive/serrated edges. Branches/organoid in 3D culture were counted and represented as bar graphs $* p=0.002 ; N=6$ ko mice and 4 cntrl mice (MMTV-Neu) and $* p=0.0001 ; N=20$ organoids per group (DMBA/MPA). c Organoid cultures from MMTV-Neu $\mathrm{Nmi}^{\mathrm{fl} / \mathrm{fl}}$ and MMTV-Neu $\mathrm{Nmi}^{-/-}$were stained for fibrillar actin (phalloidin) to visualize invasive processes. DAPI was used to stain nuclei. Representative confocal images of organoids from control and knockout models are presented. $\mathbf{d}$ Tumor cells from MMTV-Neu control and knockout mice were separated into single cells using $0.25 \%$ trypsin/EDTA and dispase II $(5 \mathrm{mg} / \mathrm{ml})$ and placed $(50,000$ cells) into Boyden chambers using fibronectin $(10 \mu \mathrm{g} /$ $\mathrm{ml}$ ) as a chemoattractant. Cells were allowed $24 \mathrm{~h}$ to invade through the matrigel coated chambers, fixed with $4 \%$ PFA and stained with crystal violet (the experiment was repeated independently) $N=5$ control tumors and 4 knockout tumors. Quantification of invasion is a measure of the percentage of cells that invaded. $* p=0.001$

population while also exhibiting fewer luminal cells (Fig. 7a), thus indicating that Nmi loss might hamper luminal differentiation (or skew the balance of differentiation) in this model as well.

The MMTV-neu model is initiated by a small population of progenitor cells positive for CD61 and expressing high levels of CD49f (Supplementary Fig. 4A). This population is capable of recapitulating a more diverse population of cells containing a wider array of CD49f and CD61 expression levels in xenograft models indicating that they differentiate in vivo [14]. It remains unclear whether these cells are luminal progenitors or early alveolar progenitor cells. However, previous studies have identified this 
population as a specific call type termed "parity-induced mammary epithelial cells". MMTV-neu tumors are characteristically homogeneous and represent the luminal, as well as HER2-enriched molecular subtypes of breast cancer [15]. Fluorescence-activated cell sorting (FACS) analysis of tumors from control and knockout mice showed that the Nmi null tumors contained 25\% more CD61+CD49f high cells compared with control tumors (Fig. 7b). Nmi loss therefore may be blocking differentiation of this particular luminal cell population during tumorigenesis in the MMTV-Neu model.
As Wnt signaling is a critical component of stemness and maintenance of the basal population in the mammary gland, we hypothesized that the loss of differentiation following Nmi knockout was due to $\beta$-catenin activity [16]. To discern whether the activated Wnt signaling seen in pre-neoplastic glands persisted in the primary mammary tumors, total $\beta$ catenin staining was performed on sections from the MMTV-Neu and carcinogen-induced models (Fig. 7c, d). In both cases, Nmi loss increased nuclear $\beta$-catenin staining (approximately 25\%) compared with Nmi-expressing controls. The effect of activated $\beta$-catenin in carcinogen-
A

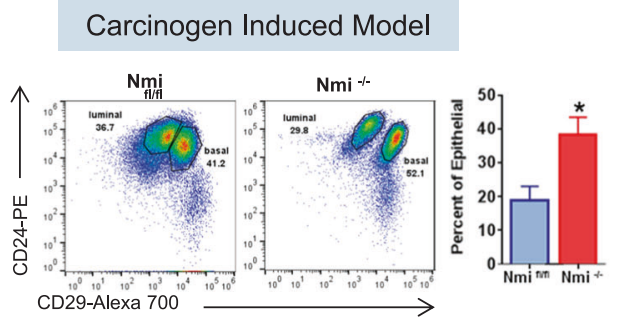

c
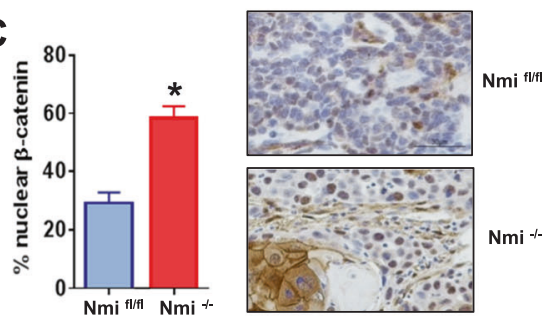

E

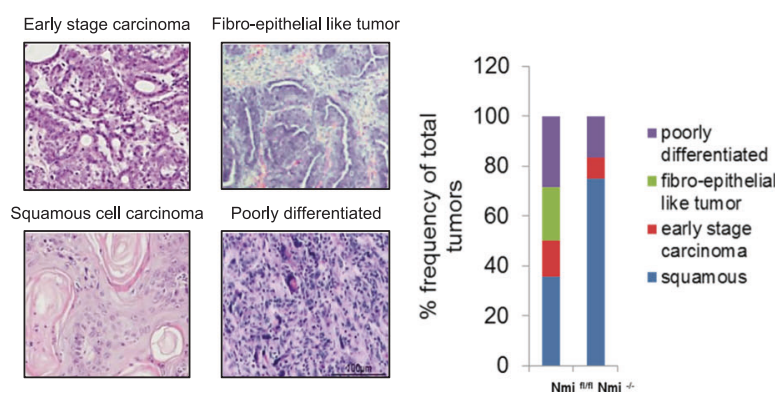

Fig. 7 Carcinogen and MMTV-Neu Nmi null tumors contain less differentiated cell populations. a Carcinogen-induced tumors were dissociated into single-cell suspension. These cells were stained with CD24 and CD29 antibodies to distinguish luminal and basal populations. $\left(n=7 \mathrm{Nmi}^{\mathrm{fl} / \mathrm{fl}}\right.$ and $\left.4 \mathrm{Nmi}^{-/-}\right)$. $* p=0.01$. b Mammary tumors from MMTV-Neu control and knockout mice were dissociated into single cells and stained for lineage markers (CD61 and CD49f) and analyzed by flow cytometry. Quadrant gates were positioned based on positivity of the fluorescence minus one controls; the double-positive population is plotted as percentage of total epithelial cells. Quantification shows a $25 \%$ increase in CD61 CD49f double-positive cells in the knockout tumors compared with control $(n=4$ MMTV-Neu $\mathrm{Nmi}^{\mathrm{fl} / \mathrm{fl}}$ and $7 \mathrm{MMTV}-\mathrm{Neu} \mathrm{Nmi}^{-/-}$). $* p=0.01$. Immunohistochemical staining of $\beta$-catenin in carcinogen-induced tumors $n=4 \mathrm{Nmi}^{-1-}$ and $7 \mathrm{Nmi}^{\mathrm{l} / \mathrm{fl}}$ mice $p=0.01$ and $\mathbf{d}$ MMTV-neu model was performed. The

D
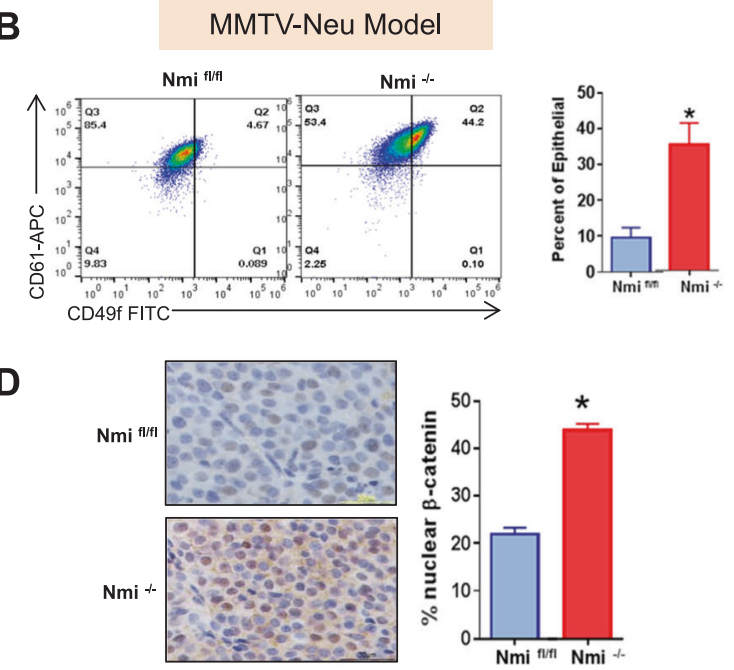

$\mathbf{F}$

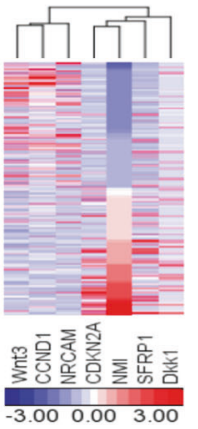

\begin{tabular}{|c|c|c|c|c|c|}
\hline $\begin{array}{c}\text { Column } \\
\text { ID }\end{array}$ & $\mathrm{r}$ & p.eve & $\mathrm{erCl}$ & ercl & \\
\hline CCND1 & .0 .26225 & $236 E-08$ & -0.347225 & $\cdot 0.173008$ & 440 \\
\hline Wni3 & .0 .25656 & $4.82 E-08$ & -0.341843 & -0.167078 & 440 \\
\hline NRCAM & -0.23315 & $7.61 \mathrm{E}-07$ & -0.319668 & -0.142776 & 440 \\
\hline Dkk1 & 0.182576 & 0.00011751 & 0.090637 & 0.271429 & 440 \\
\hline SFRP1 & 0.220617 & 2.98E-06 & 0.129808 & 0.307755 & 440 \\
\hline CDKN2A & 0.414216 & 1.14E-19 & 0.333651 & 0.488775 & 440 \\
\hline
\end{tabular}

sections were scored for percent nuclear 13-catenin. $* p=0.0001 ; N=4$ MMTV- Neu Nmi ${ }^{\mathrm{fl} / \mathrm{fl}}$ and $7 \mathrm{MMTV}-\mathrm{Neu} \mathrm{Nmi}^{-/-}$. e DMBA/MPA carcinogen-induced tumors from $\mathrm{Nmi}^{\mathrm{fl} / \mathrm{fl}}$ and $\mathrm{Nmi}^{-/-}$genetic background were evaluated for their histological categories. Photomicrographs representing the four major histologic categories are shown. Stacked bar graph represents the percent abundance of specific histological category. $\mathbf{f}$ The TCGA data set of breast invasive carcinoma (BRCA, $n=880$ ) were downloaded and used for generation of the heat map and correlation coefficients. The FPKM-normalized values were used and hierarchical clustering was performed on samples by using PARTEK genomic suite (PGS, St. Louis, MO, USA). The NMI expression was shown as ranked from low (blue) to high (red). Only those samples with NMI expression ranked as top or low $25 \%$ ( $n$ $=440$ ) were used. Pearson correlation methods were used to generate correlation coefficients (r) 
induced Nmi tumors produced a significant difference in the histological subtype of tumors formed. Seventy percent of carcinogen-induced Nmi knockout tumors exhibited squamous differentiation (Fig. 7e). Interestingly, the effect of active $\beta$-catenin on squamous differentiation of normal mammary epithelium and mammary tumors has been observed previously by numerous groups [9, 17]. These results suggest that loss of Nmi augments an activation of Wnt/ $\beta$-catenin signaling, which maintains the cells in a dedifferentiated state ultimately leading to the formation of mammary tumors with squamous differentiation.

We queried TCGA data set for breast invasive carcinoma to evaluate if displays an activation of Wnt signaling in correlation with loss of NMI expression. Interestingly, we observed a broad impact of NMI loss on Wnt/ $\beta$-catenin signaling. Expression of secreted Wnt inhibitors, Dkk1 and SFRP1, was directly correlated with NMI levels in breast tumors, whereas the Wnt ligand, Wnt3, expression inversely correlated with NMI levels. Interesting correlations with Wnt/ $\beta$-catenin signaling target genes were also revealed. Cyclin D1, a bona fide target of $\beta$-catenin transcription and neuronal cell adhesion molecule (NRCAM) another known target of $\beta$-catenin-driven transcription showed inverse correlation with NMI expression. Cyclin-dependent kinase inhibitor 2A (CDKN2A) has been shown to be downregulated by active Wnt signaling and that showed a direct correlation with loss of NMI expression (Fig. 7f).

\section{Discussion}

The mammary ductal tree is a highly dynamic structure that develops largely postnatally. Although many studies have focused on elucidating mechanisms of normal mammary development, only a limited number of studies have focused on how aberrations in this developmental process contribute to breast cancer initiation and progression. In vivo investigations of the mammary epithelial lineage have determined that lineage restricted stem/progenitor cells give rise to the luminal and basal compartments of the mammary ductal tree [18]. Detailed characterization and molecular profiling of these compartments have identified similarities between populations within the epithelial hierarchy and different molecular subtypes of breast cancer [19]. Gene expression studies have shown that most subtypes of breast cancer arise from the luminal lineage, and therefore it is essential to further understand the process of luminal differentiation, as well as critical molecules that contribute to the function of luminal cells [19].

Nmi impacts multiple signaling pathways in a contextdependent manner $[3,20]$. In particular, recent work from Zhao et al. shows divergent results in hepatocellular carcinoma where knockdown of Nmi may inhibit pulmonary metastasis, an interesting observation that highlights the cell and tumor type-specific role of Nmi in cancer [21]. Our study brings to light very important contributions of $\mathrm{Nmi}$ expression in mammary development and defines a phenotypic consequence of its loss on tumor progression and metastasis. We have studied this in various models that were generated to interrogate the consequence of absence of Nmi. We observed that Nmi knockdown in murine mammary epithelial cells, $\mathrm{HC} 11$, renders them incapable of proper differentiation. In agreement with this, the Nmi knockout mice show an increased progenitor population (25\% increase); more specifically, the parity-induced mammary epithelial cells (PI-MECs) are increased. Through careful characterization of our mammary-specific Nmi knockout model, we demonstrate that Nmi has a distinct role of restricting $\mathrm{Wnt} / \beta$-catenin signaling in vivo, particularly in PI-MECs that make up a component of the luminal lineage.

Evidence from multiple studies supports the notion that tertiary buds and their subsequent alveolar counterparts are niches for cells with stem-like properties [22, 23]. Moreover, in vivo reporter assays confirmed the presence of mammary stem cells in alveolar buds during early and mid pregnancy $[24,25]$. Prior to the onset of pregnancy, mammary glands are exposed to cycling ovarian steroid hormones, which results in the formation of numerous tertiary buds, the precursors to alveoli, during diestrus. In limiting dilution assays, epithelial cells from glands in diestrus had a significantly greater capacity for repopulation upon transplant into cleared fat pads compared with cells isolated from glands in estrus [22]. These studies support a theory that tertiary buds and alveoli formation are concomitant with an expansion of cells with stem-like characteristics.

Wnt signaling is a critical determinant of the balance between proliferation and differentiation of the mammary ductal epithelium [26]. Activated Wnt/ $\beta$-catenin signaling has been implicated and extensively studied in mammary cancer. However, the key contributions of Wnt regulators (modulators) during mammary gland development and cancer progression have been less understood. Interestingly, aberrations in mammary epithelial differentiation caused by Nmi loss results in a precocious alveolar phenotype similar to that phenotype observed in models of activated $\beta$-catenin signaling [8, 19]. Results from BAT-gal mice in the background of heterozygous and homozygous deletion of Nmi confirm that Nmi loss enhances active Wnt/ $\beta$-catenin signaling in the mammary epithelium. Molecularly, NMI expression in patients positively correlates with Dkk1 and SFRP1, two potent secreted inhibitors of $\mathrm{Wnt} / \beta$-catenin signaling. Dkk1 has a prominent role in mammary development, and when ectopically expressed can completely abolish the formation of the ductal tree during embryogenesis [27]. Similarly, SFRP1 expression changes also 
have profound effects on mammary development. Interestingly, Nmi knockout mice phenocopy SFRP1 knockout mice through the development of a precocious alveolar phenotype. Without SFRP1 expression nonparous mammary glands exhibit clear lobulo-alveolar development [28]. Furthermore, both Dkk1 and SFRP1 suppress autocrine Wnt signaling in breast cancer cells [29]. In addition to positively correlating with Wnt inhibitor expression, NMI levels in patient tumors inversely correlate with expression levels of Wnt3 ligand, a factor that is known for imparting self-renewal capabilities to mammary epithelial cells [30]. CCND1, CDKN2A, and NRCAM are all established Wnt/ $\beta$-catenin target genes. Although CCND1 and NRCAM are reported to be upregulated by $\beta$-catenin, CDKN2A is downregulated with active Wnt signaling [31-33]. Our data show that low NMI levels in patient breast tumors corresponds to increased CCND1 and decreased CDKN2A, a result of which would profoundly impact cell cycle progression. In concordance with these findings, our model shows that mammary-specific Nmi loss does accelerate tumor growth on the MMTV-Neu background and early tumor incidence in both carcinogen, as well as MMTV-Neu models.

Congruent with our findings, Wnt/ $\beta$-catenin signaling activation was seen in Nmi knockout model during lactation, as well as in tertiary buds of MMTV-Neu/Nmi ${ }^{-/-}$ glands. Wnt responsiveness has previously been observed within the myoepithelial and stromal compartments of the pubertal mammary gland [30]. Moreover, Wnt signaling was recently implicated in facilitating early dissemination and metastasis in the MMTV-Neu model [34, 35]. These recent studies represent an evolution of our understanding of the metastatic cascade and underscore the need for further investigate genetic regulators of drivers of tumor progression in order to design efficacious drugs to target metastasis.

Luminal progenitor cells are thought to give rise to all molecular subtypes of breast cancer except claudin low tumors [36]. Thus, luminal progenitor cells contribute to a substantial amount of metastatic breast cancers and it is essential to understand how these cells contribute to tumor progression. Spontaneous mammary tumor models have provided mechanistic insight into the impact of luminal differentiation on metastasis. The MMTV-PyMT spontaneous tumor model forms exclusively luminal tumors, and has one of the highest metastatic rates of any model of mammary tumorigenesis. Moreover, abrogating luminal differentiation by knocking out critical luminal cell fate transcription factors GATA-3 and ELF5 leads to significantly enhanced metastasis in vivo [37-39].

Overall our study shows that understanding the nature of normal mammary epithelial cell development will give insight into tumor behavior and characteristics. This will open the possibility to identify novel therapeutic targets.

\section{Materials and methods}

\section{Animals}

K-14 Cre (B6N.Cg-Tg(KRT14-cre)1Amc/J, stock no: 018964), MMTV-Neu (FVB/N-Tg(MMTVneu)202Mul/J, stock no: 002376), and BAT-Gal (B6.Cg-Tg(BAT-lacZ) 3Picc/J, stock no. 005317) mice were purchased from Jackson Labs. All mice were bred and maintained in the University of Alabama at Birmingham (UAB) Animal Facility in accordance with the guidelines of the IACUC. In the article, use of ${ }^{-/-}$notation means that the animals are fl/ fl, cre+and knockout confirmed.

\section{Studies with carcinogen-induced mammary tumor model}

To induce tumors with carcinogen, 6-week-old control and Nmi knockout FVB/N mice were subcutaneously implanted with a $50 \mathrm{mg} / 90$-day release medroxyprogesterone acetate pellet (Innovative research of America, Sarasota, FL). At 9, 10,12 , and 13 weeks of age, mice were administered $1 \mathrm{mg}$ DMBA dissolved in sesame oil by oral gavage. Tumor growth was measured three times weekly with digital calipers and reported as mean tumor diameter. All experiments were conducted with the approval, and according to the guidelines of the UAB-IACUC.

\section{Antibodies}

The following antibodies were used: $\beta$-catenin $6 \mathrm{~B} 3$ rabbit mAb (1:5000), Ki67 D3B5 rabbit mAb (1:500) (Cell Signaling Technology, Boston, MA, USA), $\beta$-casein M-14 (1:5000) (Santa Cruz Biotechnology), phospho $\beta$-catenin serine 552 (1:1000) (Cell Signaling Technology), and $\beta$ actin mouse monoclonal antibody (1:100 000) (Sigma Aldrich, St Louis, MO, USA).

\section{Histology and whole mounting of mammary glands}

Mammary glands were fixed in $4 \%$ paraformaldehyde, embedded in paraffin, sectioned, and stained with H\&E. For whole-mount analysis, inguinal mammary glands were dissected from mice of the indicated stage of mammary development, and fixed using Carnoy's fixative for $1 \mathrm{~h}$ at room temperature. Glands were then stained in carmine aluminum stain overnight at room temperature, dehydrated through graded ethanols $(70,80,90$, and $100 \%$ for $1 \mathrm{~h}$ at room temperature), and cleared in xylene overnight. Glands 
were mounted using Permount (Fisher Scientific) mounting medium.

\section{Immunohistochemistry and immunofluorescence}

Immunohistochemical detection of $\mathrm{Nmi}$ was performed using the Dako Envision Dual Link System-HRP system with the labeled polymer-HRP anti-rabbit (Dako). Sections $(5 \mu \mathrm{m})$ were immunostained with the Nmi antibody at a dilution of 1:200 overnight at $4{ }^{\circ} \mathrm{C}$ after antigen retrieval. Immunofluorescence was performed on formalin-fixed paraffin-embedded (FFPE) sections using Alexafluor secondary detection reagents and mounted with Vectashield mounting medium (Vector Labs, Burlingame, CA, USA). Images were captured using a Nikon Eclipse Ti inverted microscope (Nikon, Tokyo, Japan).

\section{X-gal staining}

Mammary glands were dissected, fixed in $2 \%$ paraformaldehyde (PFA) with $0.2 \%$ glutaraldehyde at room temperature before embedding in optimal cutting temperature (Tissue-Tek® O.C.T.). Sections $(20 \mu \mathrm{m})$ were cut and washed three times with phosphate-buffered saline (PBS) $0.02 \%$ NP40, $0.01 \%$ Na deoxycholate (Sigma Aldrich), and $2 \mathrm{mM} \mathrm{MgCl}_{2}$ for $2 \mathrm{~min}$. X-gal staining ( $\left.1 \mathrm{mg} / \mathrm{ml}\right)$ was performed at $37^{\circ}$ overnight in a humidified chamber in the dark. Sections were counterstained with nuclear fast red (Sigma Aldrich) and dehydrated through graded ethanols before mounting in cytoseal (Richard Allen Scientific).

\section{Alveologenesis assay and 3D culture}

Mammary epithelial cells were isolated from 12- to 14week-old nonparous mice and embedded (200 organoids per well) in Matrigel (BD Biosciences, San Jose, CA) in a 96-well plate, and allowed to solidify for $30 \mathrm{~min}$. Organoid growth medium $(150 \mu \mathrm{l}$ per well, Dulbecco's modified Eagle's medium (DMEM)/F12, 5\% fetal bovine serum, insulin-transferrin-sodium selenite (ITS) (Sigma Aldrich), gentamycin $(50 \mu \mathrm{g} / \mathrm{ml})$, penicillin/strepomycin, fungizone (Life Technologies, Carlsbad, CA, USA) was overlaid and incubated for $24 \mathrm{~h}$. Alveologenesis medium (DMEM/F12, ITS, gentamycin $(50 \mu \mathrm{g} / \mathrm{ml})$, pen/strep, fungizone $)$ including growth factors (9 nM FGF10 (Life Technologies), $9 \mathrm{nM}$ bFGF, $9 \mathrm{nM}$ TGFa, and $9 \mathrm{nM}$ recombinant mouse prolactin (Sigma Aldrich)) was added, and replaced every third day. Images were captured on the seventh day after seeding.

\section{RNASeq analysis}

Global RNAseq analysis from enriched mammary epithelial organoids from L1 was performed. Second and third mammary glands were used from wild-type and $\mathrm{Nmi}$ knockout mice (three mice per group) on the first day of lactation, minced and dissociated in digestion medium (Hank's balanced salt solution containing collagenase I (Sigma Aldrich) $(1 \mathrm{mg} / \mathrm{ml})$ and Pronase (Sigma Aldrich) $(0.1 \mathrm{mg} / \mathrm{mL})$ for $2 \mathrm{~h}$ at $37^{\circ} \mathrm{C}$ with shaking. Epithelial organoids were washed in PBS and enriched by pulse centrifugation to $1500 \mathrm{rpm}$ at least three times before subsequent assays. mRNA sequencing was performed on the Illumina HiSeq2500 using the latest versions of the sequencing reagents and flow cells. The quality of the total RNA was assessed using the Agilent 2100 Bioanalyzer. Total RNA with a RNA integrity number (RIN) of $\geq 7.0$ was used for the RNA library prep that started with two rounds of poly A+selection to isolate the mRNA. The SureSelect Strand-Specific mRNA library generation kit was used as per the manufacturer's instructions (Agilent, Santa Clara, CA, USA) to generate the sequence ready libraries. The complementary DNA libraries were quantitated using quantitative PCR in a Roche LightCycler 480 with the Kapa Biosystems kit for library quantitation (Kapa Biosystems, Woburn, MA, USA) prior to cluster generation. mRNA sequencing was done on the Illumina HiSeq2500 with onboard clustering by loading $11 \mathrm{pM}$ of the pooled libraries and paired end $50 \mathrm{bp}$ sequencing by standard techniques (Illumina, Inc., San Diego CA, USA). Approximately 30 million reads were generated per sample. The accession code for the RNA Seq data deposited in GEO database is GSE104238.

\section{Invasion assay}

Epithelial cells from mammary tumors were harvested from MMTV-Neu Nmi knockout and control mice and dissociated into single cells using $0.25 \%$ trypsin/EDTA and dispase II $(5 \mathrm{mg} / \mathrm{ml}$, Sigma). In each invasion chamber, 50,000 cells were seeded. Cells were allowed to invade through Matrigel coated $8 \mu \mathrm{M}$ polyethylene terpthalate filters (BioCoat ${ }^{\mathrm{TM}}$ Matrigel Invasion Chambers, BD Pharmingen) for $16 \mathrm{~h}$ followed by fixing in $4 \%$ PFA and staining with $0.05 \%$ crystal violet. Fibronectin $(10 \mu \mathrm{g} / \mathrm{mL})$ was used as a chemoattractant.

\section{Flow cytometry}

FACS analysis was done using an Attune Nxt flow cytometer (Thermo Fisher). Mammary epithelial cells were dissociated into single cells using $0.25 \%$ trypsin/EDTA and Dispase II ( $5 \mathrm{mg} / \mathrm{ml}$, Sigma) and stained with with the following antibodies: CD24-PE, CD49f-FITC (BD Biosciences) CD61-APC, CD14-FITC, CD29- Alexa700, Sca-1BV510, and CD117-BV405 (Biolegend, San Diego, CA, USA). 


\section{Statistical analysis}

The results were reported as mean \pm s.d. or mean \pm s.e.m., and are indicated in the figure legends. A two-sided unpaired $t$-test was used for comparison among different data sets unless otherwise specified. Log-rank test was used for Kaplan-Meier curve analysis of tumor-free mammary glands. Data were plotted using GraphPad Prism (La Jolla, CA, USA). The observations were rendered statistically significant for $p<0.05$. To calculate the necessary sample size for proposed experiments, we considered an analysis of variance model with two groups. If we are planning for $N=$ 12 mice per group. For an effect size of 0.57 , this sample size will be sufficient to provide $80 \%$ power at significance level of 0.05 (using NQuery Advisor). Prior to any analyses, the first step consisted of a check of data quality. The data were examined for outliers, and consistency between replicates. Data were summarized using descriptive statistics (mean, standard deviation, median, minimum, and maximum values) for continuous variables and tables of counts and frequencies for categorical variables. For comparisons of central tendencies, normally distributed data sets were analyzed using unpaired two-sided Student's $t$-tests under assumption of equal variance. Non-normally distributed data sets were analyzed using non-parametric Mann-Whitney $U$-tests. The normality of data set was evaluated visually using Q-Q plots and tested statistically using Shapiro-Wilk tests. The metastasis counts and other comparative studies (mammary ductal area, branching etc.) were verified by independent counting by a blinded investigator.

Acknowledgements We acknowledge Sarah K. Bailey and Ann Hanna for their assistance during experimental procedures. We are grateful to Dr. Jeffrey Rosen and his graduate student Daisy for advice with X-gal staining of mammary tissues. We acknowledge the following grant support: Cancer Center Core grant CA013148, for the Heflin Genomics facility and UAB-Transgenic and knockout facility, to RAK. Support from UAB CCTS award \#UL1TR001417 to DC BX003374 (VA) and CA194048 (NCI/NIH) to RSS and CA169202 (NCI/NIH) to LAS. HCP is a HHMI-Med-To-Grad Fellow (UAB).

Author contributions H.C.P., B.J.M. and R.S.S. designed experiments and analyzed data. H.C.P., B.J.M and S.E.W. performed the experiments. D.C analyzed the RNAseq and TCGA data and performed bioinformatic analysis. R.A.K. provided support and guidance in planning and maintaining mice strains. L.A.S and S.W. provided reagents and expertise. SEW performed pathologic evaluation of specimens. H.C.P., L.A.S and R.S.S wrote and edited the manuscript.

\section{Compliance with ethical standards}

Conflict of interest The authors declare that they have no competing interests.

Open Access This article is licensed under a Creative Commons Attribution-NonCommercial-NoDerivatives 4.0 International License, which permits any non-commercial use, sharing, distribution and reproduction in any medium or format, as long as you give appropriate credit to the original author(s) and the source, and provide a link to the Creative Commons license. You do not have permission under this license to share adapted material derived from this article or parts of it. The images or other third party material in this article are included in the article's Creative Commons license, unless indicated otherwise in a credit line to the material. If material is not included in the article's Creative Commons license and your intended use is not permitted by statutory regulation or exceeds the permitted use, you will need to obtain permission directly from the copyright holder. To view a copy of this license, visit http://creativecommons.org/licenses/by-nc-nd/4.0/.

\section{References}

1. Leonard M-hZSJMBWJ. Functional association of Nmi with Stat5 and Stat 1 in IL-2 and IFNgamma-mediated Signaling. Cell 1999;96:121-30.

2. Lebrun SJ, Shpall RL, Naumovski L. Interferon-induced upregulation and cytoplasmic localization of Myc-interacting protein Nmi. J Interferon Cytokine Res. 1998;18:767-71.

3. Pruitt HC, Devine DJ, Samant RS. Roles of N-Myc and STAT interactor in cancer: from initiation to dissemination. Int $\mathrm{J}$ Cancer 2016;139:491-500.

4. Devine DJ, Rostas JW, Metge BJ, Das S, Mulekar MS, Tucker $\mathrm{JA}$, et al. Loss of $\mathrm{N}-\mathrm{Myc}$ interactor promotes epithelialmesenchymal transition by activation of TGF-beta/SMAD signaling. Oncogene 2014;33:2620-28.

5. Hou J, Wang T, Xie Q, Deng W, Yang JY, Zhang SQ, et al. NMyc-interacting protein (NMI) negatively regulates epithelialmesenchymal transition by inhibiting the acetylation of NF-kappaB/p65. Cancer Lett 2016;376:22-33.

6. Lin VTG, Pruitt HC, Samant RS, Shevde LA. Developing cures: targeting ontogenesis in cancer. Trends Cancer 2017;3:126-36.

7. Chamorro MN, Schwartz DR, Vonica A, Brivanlou AH, Cho KR, Varmus HE. FGF-20 and DKK1 are transcriptional targets of betacatenin and FGF-20 is implicated in cancer and development. EMBO J 2005;24:73-84.

8. Teuliere J, Faraldo MM, Deugnier MA, Shtutman M, Ben-Ze'ev A, Thiery JP, et al. Targeted activation of beta-catenin signaling in basal mammary epithelial cells affects mammary development and leads to hyperplasia. Development 2005;132:267-77.

9. van Amerongen R, Bowman AN, Nusse R. Developmental stage and time dictate the fate of Wnt/beta-catenin-responsive stem cells in the mammary gland. Cell Stem Cell 2012;11:387-400.

10. Danielson KG, Oborn CJ, Durban EM, Butel JS, Medina D. Epithelial mouse mammary cell line exhibiting normal morphogenesis in vivo and functional differentiation in vitro. Proc Natl Acad Sci USA 1984;81:3756-60.

11. Perotti C, Wiedl T, Florin L, Reuter H, Moffat S, Silbermann M, et al. Characterization of mammary epithelial cell line $\mathrm{HC} 11$ using the NIA $15 \mathrm{k}$ gene array reveals potential regulators of the undifferentiated and differentiated phenotypes. Differentiation 2009;78:269-82.

12. Lo PK, Chen H. Cancer stem cells and cells of origin in MMTVHer2/neu-induced mammary tumorigenesis. Oncogene 2013;32:1338-40.

13. Kim S, Roopra A, Alexander CM. A phenotypic mouse model of basaloid breast tumors. PLoS ONE 2012;7:e30979.

14. Lo PK, Kanojia D, Liu X, Singh UP, Berger FG, Wang Q, et al. CD49f and CD61 identify Her2/neu-induced mammary tumorinitiating cells that are potentially derived from luminal progenitors and maintained by the integrin-TGFbeta signaling. Oncogene 2012;31:2614-26. 
15. Herschkowitz JI, Simin K, Weigman VJ, Mikaelian I, Usary J, Hu $\mathrm{Z}$, et al. Identification of conserved gene expression features between murine mammary carcinoma models and human breast tumors. Genome Biol 2007;8:R76.

16. Alexander CM, Goel S, Fakhraldeen SA, Kim S. Wnt signaling in mammary glands: plastic cell fates and combinatorial signaling. Cold Spring Harb Perspect Biol. 2012;4:1-28.

17. Miyoshi K, Shillingford JM, Le Provost F, Gounari F, Bronson R, von Boehmer $\mathrm{H}$, et al. Activation of beta-catenin signaling in differentiated mammary secretory cells induces transdifferentiation into epidermis and squamous metaplasias. Proc Natl Acad Sci USA 2002;99:219-24.

18. Rios AC, Fu NY, Lindeman GJ, Visvader JE. In situ identification of bipotent stem cells in the mammary gland. Nature 2014;506:322-27.

19. Gross K, Wronski A, Skibinski A, Phillips S, Kuperwasser C. Cell fate decisions during breast cancer development. J Dev Biol. 2016;4:4.

20. Feng X, Xu X, Xiao X, Zou K, Yu W, Wu J, et al. NMI inhibits cancer stem cell traits by downregulating hTERT in breast cancer. Cell Death Dis 2017;8:e2783.

21. Zhao J, Dong QZ, Zhong F, Cai LL, Qin ZY, Liu Y, et al. NMI promotes hepatocellular carcinoma progression via BDKRB2 and MAPK/ERK pathway. Oncotarget 2017;8:12174-85.

22. Joshi PA, Jackson HW, Beristain AG, Di Grappa MA, Mote PA, Clarke CL, et al. Progesterone induces adult mammary stem cell expansion. Nature 2010;465:803-7.

23. Joshi PA, Di Grappa MA, Khokha R. Active allies: hormones, stem cells and the niche in adult mammopoiesis. Trends Endocrinol Metab 2012;23:299-9.

24. Boras-Granic K, Dann P, Wysolmerski JJ. Embryonic cells contribute directly to the quiescent stem cell population in the adult mouse mammary gland. Breast Cancer Res 2014;16:487.

25. Tiede B, Kang Y. From milk to malignancy: the role of mammary stem cells in development, pregnancy and breast cancer. Cell Res 2011;21:245-57.

26. Boras-Granic K, Wysolmerski JJ. Wnt signaling in breast organogenesis. Organogenesis 2008;4:116-22.

27. Chu EY, Hens J, Andl T, Kairo A, Yamaguchi TP, Brisken C, et al. Canonical WNT signaling promotes mammary placode development and is essential for initiation of mammary gland morphogenesis. Development 2004;131:4819-29.
28. Gauger KJ, Shimono A, Crisi GM, Schneider SS. Loss of SFRP1 promotes ductal branching in the murine mammary gland. BMC Dev Biol. 2012;12:25.

29. Bafico A, Liu G, Goldin L, Harris V, Aaronson SA. An autocrine mechanism for constitutive Wnt pathway activation in human cancer cells. Cancer Cell 2004;6:497-506.

30. Zeng YA, Nusse R. Wnt proteins are self-renewal factors for mammary stem cells and promote their long-term expansion in culture. Cell Stem Cell 2010;6:568-77.

31. Conacci-Sorrell ME, Ben-Yedidia T, Shtutman M, Feinstein E, Einat P, Ben-Ze'ev A. Nr-CAM is a target gene of the betacatenin/LEF-1 pathway in melanoma and colon cancer and its expression enhances motility and confers tumorigenesis. Genes Dev. 2002;16:2058-72.

32. Shtutman M, Zhurinsky J, Simcha I, Albanese C, D'Amico M, Pestell R, et al. The cyclin D1 gene is a target of the beta-catenin/ LEF-1 pathway. Proc Natl Acad Sci USA 1999;96:5522-27.

33. Delmas V, Beermann F, Martinozzi S, Carreira S, Ackermann J, Kumasaka $\mathrm{M}$, et al. Beta-catenin induces immortalization of melanocytes by suppressing p16INK4a expression and cooperates with N-Ras in melanoma development. Genes Dev 2007;21:2923-35.

34. Harper KL, Sosa MS, Entenberg D, Hosseini H, Cheung JF, Nobre $\mathrm{R}$ et al. Mechanism of early dissemination and metastasis in Her2+mammary cancer. Nature 2016.

35. Hosseini H, Obradovic MM, Hoffmann M, Harper KL, Sosa MS, Werner-Klein $\mathrm{M}$ et al. Early dissemination seeds metastasis in breast cancer. Nature 2016

36. Lim E, Vaillant F, Wu D, Forrest NC, Pal B, Hart AH, et al. Aberrant luminal progenitors as the candidate target population for basal tumor development in BRCA1 mutation carriers. Nat Med 2009;15:907-13.

37. Kouros-Mehr H, Bechis SK, Slorach EM, Littlepage LE, Egeblad M, Ewald AJ, et al. GATA-3 links tumor differentiation and dissemination in a luminal breast cancer model. Cancer Cell 2008;13:141-52.

38. Kouros-Mehr H, Kim JW, Bechis SK, Werb Z. GATA-3 and the regulation of the mammary luminal cell fate. Curr Opin Cell Biol 2008;20:164-70.

39. Chakrabarti R, Wei Y, Romano RA, DeCoste C, Kang Y, Sinha S. Elf5 regulates mammary gland stem/progenitor cell fate by influencing notch signaling. Stem Cells 2012;30:1496-508. 